\title{
Determination of Bus Voltages, Real and Reactive Power Losses in the Northern Nigeria 330Kv Network Using Power System Analysis Tool (PSAT)
}

\author{
Ishaku Bello ${ }^{1, ~ *, ~ M u s a ~ B u k a r ~ U m a r ², ~ H a r r i s o n ~ O y i b o ~ I d a k w o ~}{ }^{1}$ \\ ${ }^{1}$ Dept. of Engineering Services University of Maiduguri Teaching Hospital, Maiduguri, Nigeria \\ ${ }^{2}$ Dept. of Elect/Elect Engineering University of Maiduguri, Maiduguri, Nigeria \\ Email address: \\ ishakubello@gmail.com (I. Bello), musabukar@unimaid.edu.ng (M. B. Umar), idakwoharrison@gmail.com (H. O. Idakwo) \\ ${ }^{*}$ Corresponding author
}

\section{To cite this article:}

Ishaku Bello, Musa Bukar Umar, Harrison Oyibo Idakwo. Determination of Bus Voltages, Real and Reactive Power Losses in the Northern Nigeria 330Kv Network Using Power System Analysis Tool (PSAT). Science Journal of Energy Engineering. Vol. 4, No. 5, 2016 , pp. 35-43. doi: $10.11648 /$ j.sjee.20160405.11

Received: September 16, 2016; Accepted: October 27, 2016; Published: November 17, 2016

\begin{abstract}
The power system analysis and design is generally done by using Load flow studies. The essence of power flow analysis is to find the magnitude and phase angle of voltage at each bus and the real and reactive power flows in each transmission lines. Therefore, load flow analysis is an important tool involving numerical analysis applied to a power system. This analysis is being executed at the stage of planning, operation, control and economic scheduling. Load flow analysis is performed on a symmetrical steady state operating condition of a power system under normal operating condition. This information is essential for the continuous monitoring of the current state of the system and for analyzing the effectiveness of alternative plans for future system expansion to meet increased load demand. For power flow analysis, this research considered the $330 \mathrm{KV}$ of northern Nigeria transmission network with a view of estimating the real and reactive power flows, power losses in the entire network and phase angle using Power System Analysis Toolbox (PSAT).
\end{abstract}

Keywords: Load Flow Analysis, Transmission Network, PSAT, Bus Voltages, Power Losses

\section{Introduction}

Nigeria is a vast country with a total of 356,667 square miles $\left(923,768 \mathrm{~km}^{2}\right)$, of which 351,649 sq. miles $(910,771$ square $\mathrm{km}$ or $98.6 \%$ of total area) is land. The nation is made up of six geo-political zones subdivided into 36 states and the Federal Capital Territory (F. C. T.). Furthermore, the vegetation cover, physical features and land terrain in the nation vary from flat open savannah in the North to thick rain forests in the south, with numerous rivers, lakes and mountains scattered all over the country with population of $162,470,737$ Million people. The total installed capacity of the currently generating plants is $9,065 \mathrm{MW}$, but the available capacity is around $3,885 \mathrm{MW}$ with peak value of 4,477.7 MW as at on 15th August 2014. Seven of the fourteen generation stations are over 20 years old and the average daily power generation is below $4,000 \mathrm{MW}$, which is far below the peak load forecast of $8,900 \mathrm{MW}$ for the currently existing infrastructure. As a result, the nation experiences massive load shedding [1]. Currently, only about 40 percent of Nigeria's total population has access to public electricity supply due to inadequate transmission and distribution networks. Also ageing infrastructure, weak and radial network configuration, and overloaded transformers result in frequent system collapse, with high transmission and distribution losses and poor voltage profile. Currently, with some of the completed integrated power projects, the Nigeria national grid is an interconnection of $9,454.8 \mathrm{KM}$ length of $330 \mathrm{kV}$ and $8,985.28 \mathrm{~km}$ length of $132 \mathrm{kV}$ transmission lines with seventeen power stations. The grid interconnects these stations with fifty two buses and sixty four transmission lines of either dual or single circuit lines and has four control centers (one national control center at Oshogbo and three supplementary control centers at Benin, Shiroro and Egbin). The current projection of power generation by $\mathrm{PHCN}$ is to generate $26,561 \mathrm{MW}$ as envisioned in the vision 20: 2020 
target. Presently, of the seventeen (17) active power generating stations, eleven of these are owned by the Federal Government of Nigeria (FGN), with installed capacity of 6,904.6MW and 2,271MW. The remaining six (6) is from National Integrated Power Project (NIPP) with total designed capacity of $4,775 \mathrm{MW}$, of which $1,483 \mathrm{MW}$ is available. These generating stations are sometimes connected to load centers through either very long or inadequate transmission lines. The transmission network is overloaded with a wheeling capacity of 4,000MW. It has poor voltage profile, inadequate dispatch and control infrastructure, radial and fragile grid network, frequent system collapse, exceedingly high transmission losses which is as high as 25 percent compared with 3 percent in the US, 0.5 percent in Japan and 0.4 percent in South Korea due to low transmission grid voltages and long distances over which electrical energy is distributed in the country. The northern part of Nigeria is mainly dominated by hydro power plant located in Jebba, Shiroro and Kainji all in Niger state. The three hydro power plants have a total installed capacity of $1864 \mathrm{MW}$ but the total available capacity is $1013 \mathrm{MW}$ [2]. Power flow analysis is one of the most important aspects of power system planning and operation. The load flow provides us the sinusoidal steady state of the entire system- voltages, real, reactive powers and line losses. It provides solution of the network under steady state condition subjected to certain inequality constraints such as nodal voltages, reactive power generation of the generators and gives the voltage magnitudes and angles at each bus in the steady state. This is rather important as the magnitudes of the bus voltages are required to be held within a specified limit. The following parameters can be determined in power flow study: Power flows in all branches in a network, power contributed by each generator, power losses in each component in the network and nodal voltages magnitudes and angles throughout the network [3].

Due to the above, new strategies, new methods of analysis and design are being sought to improve performance of power system.

According to [4]: in their work on power flow analysis of the Nigerian transmission system, concluded that incorporating FACTS devices are adequately enough to improve the power demand of the country.

Also in [5]: they identify poor power magnitude at Gombe, Kano, Jos, Kaduna and Katampe transmission station. Voltage violations were also improved by adding shunt capacitor compensators to the affected buses. The northern Nigeria is expanding with increase in agriculture output as a result more industries are coming up, adding shunt capacitor compensators can be a lasting solution to this problem.

In [6]: they study the steady state voltage stability enhancement using SSSC, upon running load flow, they discover that some buses recorded voltage drop, but upon incorporating SSSC device there was significant improvement.

According to [7]: he run a load flow analysis of $230 / 110 \mathrm{kv}$ substation using ETAP, he end up by recommending only capacitor bank for the correction of under voltage.

According to [8]: they look at the behavior of the national grid before and after reform (unbundling of the power sector and the recent concluded/abandon project), the system has great improvement with the addition more generating power plant and more $330 \mathrm{kv}$ transmission network. The work depends heavily on assume data because up to now most of the generating plant and the transmission lines are under construction.

Much research is still ongoing in the determination of bus voltages, real and reactive power losses. It is the aim of this paper to investigate bus voltages, real and reactive power losses and flows on the northern Nigeria $330 \mathrm{kv}$ network using PSAT.

In [9] a simple and efficient computer algorithm has been presented to solve unbalanced radial distribution networks. The proposed method has good convergence property for any practical distribution networks with practical $\mathrm{R} / \mathrm{X}$ ratio. Computationally, this method is extremely efficient.

\section{Review of Current Nigeria Integrated Power System}

Currently, only about 40 percent of Nigeria's total population has access to public electricity supply due to inadequate transmission and distribution networks. Also ageing infrastructure, weak and radial network configuration, and overloaded transformers result in frequent system collapse, with high transmission and distribution losses and poor voltage profile. Currently, with some of the completed integrated power projects, the Nigeria national grid is an interconnection of $9,454.8 \mathrm{KM}$ length of $330 \mathrm{kV}$ and $8,985.28 \mathrm{~km}$ length of $132 \mathrm{kV}$ transmission lines with seventeen power stations. The grid interconnects these stations with fifty two buses and sixty four transmission lines of either dual or single circuit lines and has four control centers (one national control center at Oshogbo and three supplementary control centers at Benin, Shiroro and Egbin). The current projection of power generation by $\mathrm{PHCN}$ is to generate 26,561MW as envisioned in the vision 20: 2020 target. Presently, of the seventeen (17) active power generating stations, eleven of these are owned by the Federal Government of Nigeria (FGN), with installed capacity of 6,904.6MW and 2,271MW is available. The remaining six (6) is from NIPP with total designed capacity of $4,775 \mathrm{MW}$, of which $1,483 \mathrm{MW}$ is available. These generating stations are sometimes connected to load centers through either very long or inadequate transmission lines. The transmission network is overloaded with a wheeling capacity of less than $4,000 \mathrm{MW}$. It has poor voltage profile, inadequate dispatch and control infrastructure, radial and fragile grid network, frequent system collapse, exceedingly high transmission losses which is as high as 25 percent compared with 3 per cent in the US, 0.5 in Japan and 0.4 in South Korea due to low transmission grid voltages and long distances over which electrical energy is distributed in the country. Nigeria Power industry deregulation (and re-regulation) has started the dismantling of the traditional utility business structure so 
that generation, transmission and distribution are becoming owned and operated by different entities.

\subsection{Nigerian Electric Power Transmission System}

The Nigerian electric power transmission network, operated by the Transmission Company of Nigeria (TCN), operates at a high pressure of $330 \mathrm{kV}$ while its lower transmission pressure is $132 \mathrm{kV}$. The grid is an integrated network consisting of seventeen generating stations and fifty two $330 \mathrm{kV}$ bus; two of the generating stations (Trans Amadi G. S. and Omoku G. S.) are run on island operation. Only three generating stations (Jebba, Kainji and Shiroro Hydro power stations) and eleven transmitting stations were cited in the northern part of the country as at data collection time. Three of these transmitting stations (Damaturu T.S., Maiduguri T.S., and Yola T.S.) had no record of operation as at data collection time [5].

\subsection{The Northern Nigeria Grid System}

The northern Nigerian power system of $330 \mathrm{kV}$ transmission lines is the study area in the context of this work. It consists of 3 generator and 13 bus networks. All the three (3) generators are hydro units.

\subsection{Power Balance Equations}

As shown in equation (1) and (2), the total generation of real and reactive power must be equals to the total load demand plus losses, [4, 10].

$$
\begin{aligned}
& \sum_{i=1}^{n} P G i=\sum_{i=1}^{n} P D i+P_{\text {Loss }} \\
& \sum_{i=1}^{n} Q G i=\sum_{i=1}^{n} Q D i+Q_{\text {Loss }}
\end{aligned}
$$

\subsection{Power Flow Equations}

Consider a typical bus of a power system network as shown in Figure 1.0. Transmission lines are represented by their equivalent $\pi$ models where impedances have been converted to per - unit admittances on a common MVA base.

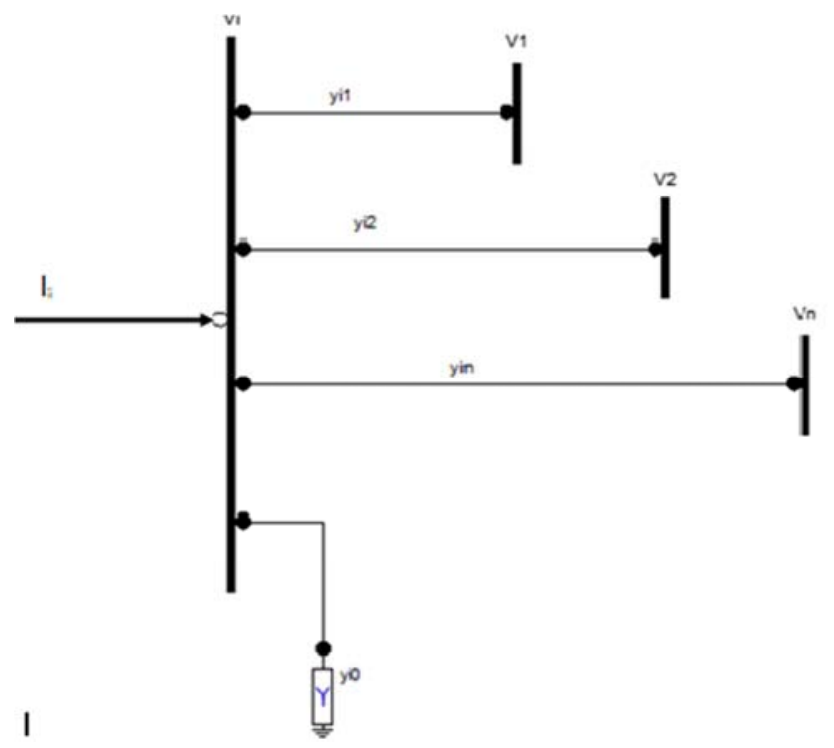

Figure 1. Typical bus of the power system.
Application of Kirchhoff's current Law (KCL) to this bus results in

$$
\begin{array}{r}
\mathrm{I}_{\mathrm{i}}=\mathrm{y}_{\mathrm{i} 0} \mathrm{~V}_{\mathrm{i}}+\mathrm{y}_{\mathrm{i} 1}\left(\mathrm{~V}_{\mathrm{i}}-\mathrm{V}_{1}\right)+\mathrm{y}_{\mathrm{i} 2}\left(\mathrm{~V}_{\mathrm{i}}-\mathrm{V}_{2}\right)+\ldots \ldots . . . \mathrm{y}_{\text {in }}\left(\mathrm{V}_{\mathrm{i}}-\mathrm{V}_{\mathrm{n}}\right) \\
=\left(\mathrm{y}_{\mathrm{i} 0}+\mathrm{y}_{\mathrm{i} 1}+\mathrm{y}_{\mathrm{i} 2}+\ldots .+\mathrm{y}_{\mathrm{in}}\right) \mathrm{Vi}-\mathrm{y}_{\mathrm{i} 1} \mathrm{~V}_{1}-\mathrm{y}_{\mathrm{i} 2} \mathrm{~V}_{2}-\ldots \ldots . . \mathrm{y}_{\mathrm{in}} \mathrm{V}_{\mathrm{n}} \\
\mathrm{I}_{\mathrm{i}}=\mathrm{V}_{\mathrm{i}} \sum_{j=0}^{n} y_{i j}-\sum_{j=1}^{n} y_{i j} V_{j}, \mathrm{~J} \not \equiv \mathrm{I}
\end{array}
$$

The apparent power at bus $\mathrm{i}$ is

$$
\mathrm{S}_{\mathrm{i}}=\mathrm{P}_{\mathrm{i}}+\mathrm{jQ}_{\mathrm{i}}=\mathrm{V}_{\mathrm{i}} \mathrm{I}^{*}{ }_{\mathrm{i}}
$$

Or

$$
\mathrm{I}_{\mathrm{i}}=\frac{P_{i}-j Q_{i}}{V_{i}^{*}}
$$

Using equation (6) in equation (5) gives

$$
\mathrm{I}_{\mathrm{i}}=\frac{P_{i}-j Q_{i}}{V_{i}{ }^{*}}=\mathrm{V}_{\mathrm{i}} \sum_{j=0}^{n} y_{i j}-\sum_{j=1}^{n} y_{i j} V_{j}, \mathrm{j} \neq \mathrm{I}
$$

From equation (8), the mathematical formulation of the power flow problem results in a system of algebraic non-linear equations which must be solved by iterative techniques.

\subsubsection{Gauss - Seidel Power Flow Solution}

In the power flow study, it is necessary to solve the set of non - linear equations represented by equation (8). In the Gauss - Seidel method equation (8) is solved for $\mathrm{V}_{\mathrm{i}}$ and the iterative sequence becomes,

$$
\mathrm{V}^{(\mathrm{k}+1)}=\frac{\frac{P^{s c h}-j Q_{i}{ }^{s c h}}{V_{i}^{*}(k)}+\sum y_{i j} V_{i j}{ }^{(k)}}{\sum y_{i j}} \mathrm{j} \neq \mathrm{I}
$$

In writing the KCL, current entering bus $\mathrm{i}$ was assumed positive. Thus, for buses where real and reactive powers are injected into the bus, such as generator buses, $\mathrm{P}^{\text {sch }}$ and $\mathrm{Q}^{\text {sch }}$ have positive values. For load buses where real and reactive powers are flowing away from the bus, $\mathrm{P}^{\text {sch }}$ and $\mathrm{Q}^{\text {sch }}$ have negative values. If equation (5) is solved for $\mathrm{P}_{\mathrm{i}}$ and $\mathrm{Q}_{\mathrm{i}}$, we have

$$
\begin{aligned}
\mathrm{P}_{\mathrm{i}}^{(\mathrm{k}+1)} & =\operatorname{Real}\left[\mathrm{V}_{\mathrm{i}}{ }^{*(\mathrm{k})}\left\{\mathrm{V}_{\mathrm{i}}^{(\mathrm{k})} \sum_{j=0}^{n} y_{i j}-\sum_{j=1}^{n} y_{i j} V_{j}^{(k)}\right\}\right] \mathrm{J} \neq \mathrm{I} \\
\mathrm{Q}_{\mathrm{i}}^{(\mathrm{k}+1)} & =\text { Imaginary }\left[\mathrm{V}_{\mathrm{i}}^{*(\mathrm{k})}\left\{\mathrm{V}_{\mathrm{i}}^{(\mathrm{k})} \sum_{j=0}^{n} y_{i j}-\sum_{j=1}^{n} y_{i j} V_{j}^{(k)}\right\}\right] \mathrm{j} \neq \mathrm{I}
\end{aligned}
$$

The bus admittance matrix $\mathbf{Y}_{\text {bus }}$ is an important network description of the interconnected power system and the power flow equation is usually expressed in terms of the elements of the bus admittance matrix, $\mathbf{Y}_{\text {bus. }}$. Since the off diagonal elements of the bus admittance matrix $\boldsymbol{Y}_{b u s}$ are $\mathrm{Y}_{\mathrm{ij}}=-\mathrm{y}_{\mathrm{ij}}$ and the diagonal elements are $Y_{i i}=\sum y_{i j}$ then equation (6) above becomes

$$
\mathrm{V}^{(\mathrm{k}+1)}=\frac{\frac{P^{s c h}-j Q_{i}{ }^{s c h}}{V_{i}^{*}(k)}+\sum y_{i j} V_{i j}{ }^{(k)}}{Y_{i j}}
$$

And equation (10) and (11) becomes

$$
\mathrm{P}_{\mathrm{i}}^{(\mathrm{k}+1)}=\operatorname{Real}\left(\mathrm{V}_{\mathrm{i}}^{*(\mathrm{k})}\left\{\mathrm{V}_{\mathrm{i}}^{(\mathrm{k})} \mathrm{Y}_{\mathrm{ii}}+\sum_{i=1, j \neq i}^{n} y_{i j} V_{j}^{k}\right\}\right) \mathrm{j} \neq \mathrm{i}
$$


$\mathrm{Qi}(\mathrm{k}+1)=\operatorname{Imaginary}\left(\mathrm{V}_{\mathrm{i}}{ }^{*}(\mathrm{k})\left\{\mathrm{V}_{\mathrm{i}}^{(\mathrm{k})} \mathrm{Y}_{\mathrm{ii}}+\sum_{i=1, j \neq i}^{n} y_{i j} V_{j}^{k}\right\}\right) \mathrm{j} \neq \mathrm{I}(13)$

$\mathrm{Y}_{\mathrm{ii}}$ includes the admittance to ground of line charging susceptance and any other fixed admittance to ground.

\subsubsection{Newton - Raphson Method}

The load flow problem can also be solved by using Newton Raphson method. For the typical bus of the power system shown in Fig. 1.0 the current entering bus written in terms of the bus admittance matrix as.

$$
\mathrm{I}_{\mathrm{i}}=\sum_{j=1}^{n} Y_{i j} V_{j}
$$

Expressing equation (15) in polar form, we have

$$
\mathrm{I}_{\mathrm{i}}=\left.\sum_{j=1}^{n}\left|Y_{i j}\right| V\right|_{i}<\theta_{i j}+\delta_{j}
$$

The complex power at bus $i$ is

$$
P_{\mathrm{i}}-j \mathrm{Q}_{\mathrm{i}}=\mathrm{V}_{\mathrm{i}}^{*} \mathrm{I}_{\mathrm{i}}
$$

Substituting equation (16) into equation (17)

$$
\mathrm{P}_{\mathrm{i}}-\mathrm{j} \mathrm{Q}_{\mathrm{i}}=\left|\mathrm{V}_{\mathrm{i}}\right|<-\delta_{i} \sum_{j=1}^{n}|Y|_{i j}|V|_{j}<\delta_{i j}+\delta_{j}
$$

Separating the real and imaginary parts

$$
\begin{gathered}
\mathrm{P}_{\mathrm{i}}=\sum_{j=1}^{n}\left|V_{i}\left\|V_{j}\right\| Y_{i j}\right| \cos \left(\theta_{i j}-\delta_{i}+\delta_{j}\right) \\
\frac{\partial P_{i}}{\partial\left|V_{i}\right|}=2\left|V_{i}\right|\left|Y_{i j}\right| \cos \theta_{i i}+\sum_{j=1}^{n}\left|V_{j}\right|\left|Y_{i j}\right| \cos \left(\theta_{i j}-\delta_{i}+\delta_{j}\right) \\
\frac{\partial P_{i}}{\partial\left|V_{j}\right|}=\left|V_{i}\right|\left|Y_{i j}\right| \cos \left(\theta_{i j}-\delta_{i}+\delta_{j}\right) \mathrm{j} \neq i
\end{gathered}
$$

$$
\mathrm{Q}_{\mathrm{i}}=-\sum_{j=1}^{n}\left|V_{i} \| V_{j}\right|\left|Y_{i j}\right| \sin \left(\theta_{i j}-\delta_{i}+\delta_{j}\right)
$$

Equation (19) and (20) constitute a set of non - linear algebraic equations in terms of the independent variables, voltage magnitude in per - unit and phase angle in radians. We have two equations for each load bus given by (19) and (20), and one equation for each voltage controlled bus, given by (19). Expanding (19) and (20) in Taylor's series about the initial estimate and neglecting all higher order terms results in a set of linear equations. These equations after linearization can be written in matrix form as.

$$
\left[\begin{array}{c}
\Delta P \\
\Delta Q
\end{array}\right]=\left[\begin{array}{c}
J_{1} J_{2} \\
J_{3} J_{4}
\end{array}\right]\left[\begin{array}{c}
\Delta \delta \\
\Delta|V|
\end{array}\right]
$$

Where element $\mathrm{J}_{1}, \mathrm{~J}_{2}, \mathrm{~J}_{3}, \mathrm{~J}_{4}$ are elements of Jacobian matrix. In obtaining the power flow solution by Newton - Raphson method, we have to consider equation (21).

The diagonal and off diagonal element of $\mathrm{J}_{1}$ are:

$$
\begin{aligned}
& \frac{\partial P_{i}}{\partial Q_{i}}=\sum_{j \neq i}^{n}\left|V_{i}\right|\left|V_{j}\right|\left|Y_{i j}\right| \sin \left(\theta_{i j}-\delta_{i}+\delta_{j}\right) \\
& \frac{\partial P_{i}}{\partial \delta_{j}}=-\left|\mathrm{V}_{\mathrm{i}}\right|\left|\mathrm{V}_{\mathrm{j}}\right|\left|\mathrm{Y}_{\mathrm{ij}}\right| \sin \left(\theta_{i j}-\delta_{i}+\delta_{j}\right) \mathrm{j} \neq i
\end{aligned}
$$

The diagonal and off diagonal element of $\mathrm{J}_{2}$ are:

The diagonal and off diagonal elements of $\mathrm{J}_{3}$ are:

$$
\begin{aligned}
& \frac{\partial Q_{i}}{\partial \delta_{j}}=\sum_{j \neq 1}^{n}\left|V_{i}\right|\left|V_{j}\right|\left|Y_{i j}\right| \cos \left(\theta_{i j}-\delta_{i}+\delta_{j}\right) \\
& \frac{\partial Q_{i}}{\partial \delta_{j}}=-\left|V_{i}\right|\left|V_{j}\right|\left|Y_{i j}\right| \cos \left(\theta_{i j}-\delta_{i}+\delta_{j}\right) j \neq i
\end{aligned}
$$

The diagonal and off diagonal element of $\mathrm{J}_{4}$ are:

$$
\begin{gathered}
\frac{\partial Q_{i}}{\partial\left|V_{i}\right|}=-2\left|V_{i}\right|\left|Y_{i i}\right| \sin \theta_{i j}+\sum_{j \neq 1}^{n}\left|V_{j}\right|\left|Y_{i j}\right| \sin \left(\theta_{i j}-\delta_{i}+\delta_{j}\right) \\
\frac{\partial Q_{i}}{\partial\left|V_{j}\right|}=-\left|V_{i}\right|\left|Y_{i j}\right| \sin \left(\theta_{i j}-\delta_{i}+\delta_{j}\right) j \neq i \quad(28) \quad \begin{array}{c}
\text { 2.4.3. Fast Decouple Newton- Raphson Power Flow } \\
\text { Solution }
\end{array}
\end{gathered}
$$

\subsubsection{Fast Decouple Newton- Raphson Power Flow Solution}

The terms $\Delta P_{i}^{(k)}$ and $\Delta Q_{i}^{(k)}$ are the differences between the scheduled and calculated values, known as the power residuals given by:

$$
\begin{aligned}
\Delta P_{i}^{(k)} & =P^{s c h}-P_{i}^{(k)} \\
\Delta Q_{i}^{(k)} & =Q^{s c h}-Q_{i}^{(k)}
\end{aligned}
$$

The new estimates for bus voltages are:

$$
\begin{gathered}
\delta_{i}^{(k+1)}=\delta_{i}^{(k)}+\Delta \delta_{i}^{(k)} \\
\left|V_{i}^{(k+1)}\right|=\left|V_{i}^{k}\right|+\Delta\left|V_{i}^{k}\right|
\end{gathered}
$$

This is an extension of Newton - Raphson method formulated in polar coordinates with certain approximation which results in fast algorithm for load flow solution. Because power system transmission lines have a very high $\mathrm{X} / \mathrm{R}$ ratio thus it is reasonably assumed that real power changes $(\Delta \mathrm{P})$ are less sensitive to changes in voltage magnitude and are mainly sensitive to changes in phase angle $(\Delta \delta)$. Similarly, the reactive power is less sensitive to changes in phase angle $\Delta \delta$ but mainly sensitive to changes in voltage magnitude. With these assumptions, recall equation (21)

$$
\left[\begin{array}{l}
\Delta P \\
\Delta Q
\end{array}\right]=\left[\begin{array}{c}
J_{1} J_{2} \\
J_{3} J_{4}
\end{array}\right]\left[\begin{array}{c}
\Delta \delta \\
\Delta|V|
\end{array}\right]
$$


Or

$$
\begin{gathered}
\Delta P=J_{1} \Delta \delta=\frac{|\delta P|}{\partial \delta} \Delta \delta \\
\Delta Q=J_{4} \Delta|V|=\frac{|\partial Q|}{\partial|V|} \Delta|V|
\end{gathered}
$$

Equations (31) and (32) show that the matrix equation is separated into two decoupled equations requiring considerably less time to solve compared to the time required for the solution of (19). Furthermore, considerable simplification can be made to eliminate the need for re-computing J1and J4 during each iteration. This procedure however, results in Fast Decoupled power flow equations [10].

\section{Methodology}

The design in the context of this paper will be limited to the northern Nigeria $330 \mathrm{Kv}$ network using PSAT, in other to achieve the following aim;

i. To determine bus voltages, real and reactive power losses and flows on the northern Nigeria $330 \mathrm{kv}$ network using PSAT

ii. To design a model that can be used to determine the actual calculation of active and reactive power.

iii. To carry out an in-depth studies on load flow analysis.

iv. To evaluate the performance of the model on the collected data.

v. To design a model that can be used to plan ahead the load demand by consumers.

\subsection{Data Collection}

The data used in this analysis and assessment were collected from Transmission company of Nigeria (TCN). These was modeled and simulated in PSAT 2.1.9 using N-R power flow algorithm. The network for this study consist of Three (3) generating stations, Thirteen (13) buses, Nine (9) loads and Twelve(12) transmission lines using N-R and modeled with Power System Analysis Toolbox (PSAT). Simulation of the designed model was carried out in other to determine the active and reactive power flows in all branches in a network, active and reactive power contributed by each generator, active and reactive power losses in each component in the network, bus voltages magnitudes and angles throughout the network.

\subsection{Design and Simulation of Northern Nigeria $330 \mathrm{KV}$ Network using N-R Method}

The Newton-Raphson method formulates and solves iteratively the following load flow equation (15-33).

Recall equation (21)

$$
\left[\begin{array}{l}
\Delta P \\
\Delta Q
\end{array}\right]=\left[\begin{array}{c}
J_{1} J_{2} \\
J_{3} J_{4}
\end{array}\right]\left[\begin{array}{c}
\Delta \delta \\
\Delta|V|
\end{array}\right]
$$

Where $\Delta \mathrm{P}$ and $\Delta \mathrm{Q}$ are bus real power and reactive power mismatch vectors between specified value and calculated value, respectively; $\Delta \mathrm{V}$ and $\Delta \delta$ represents bus voltage angle and magnitude vectors in an incremental form; and $\mathrm{J}_{1}$ through $\mathrm{J}_{4}$ are called Jacobian matrices. The Newton Raphson method possesses a unique quadratic convergence characteristic. It usually has a very fast convergence speed compared to other load flow calculation methods. It also has the advantage that the convergence criteria are specified to ensure convergence for bus real power and reactive power mismatches. This criterion gives the direct control of the accuracy method of Newton-Raphson. The convergence criteria for the Newton-Raphson method are typically set to $0.001 \mathrm{MW}$ and MVar. The Newton-Raphson method is highly dependent on the voltage initial values. Flow Chart for Newton-Raphson Algorithm used for the Northern Nigeria 330KV Network.

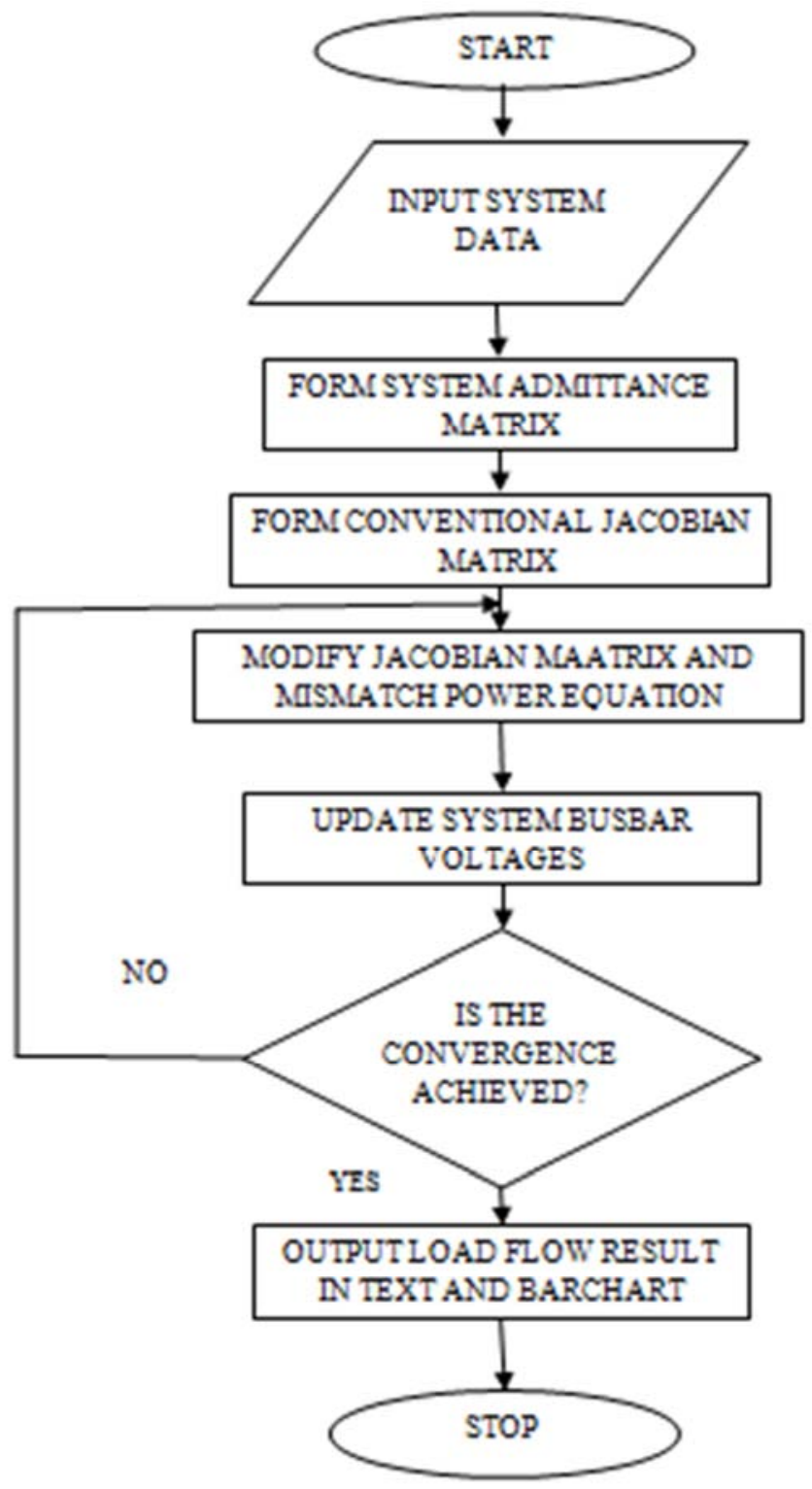

Figure 2. Flow chart for Newton-Raphson Algorithm.

\subsection{IEEE 14 Bus Test Network}

Test network system is widely used in power system research and education. It is imperative to understand the importance of using the standard test network. This is very 
vital because; Practical power systems data are partially confidential, also the dynamic and static data of the system are not well documented, more so, Calculations of numerous scenarios are difficult due to large set of data and the lack of software capabilities for handling large set of data less generic results from practical power system.

The 14 bus system consists of five synchronous machines with IEEE type; 1 exciter, four of which are synchronous compensators used only for reactive power support. There are nine load buses in the system totaling to $259 \mathrm{MW}$ and 81.3 MVAR. The dynamic and static data of the system can be found. The system is widely used for voltage stability as well as low frequency oscillatory stability analysis. The 14 bus test case does not have line limits compared to other systems. It has also a low base voltage and an overabundance of voltage control capability.

\section{Results and Discussion}

The result obtained in this section shows the power flows in the transmission lines and losses from both generators and lines. The bus voltages were also obtained to know the weak ones among them. Comparism was made between the Northern Nigeria grid and the IEEE 14 bus test system.

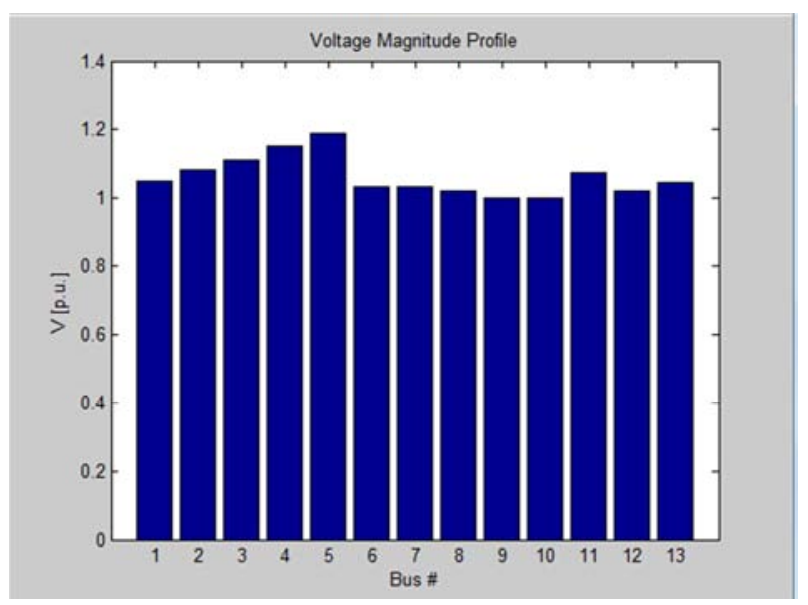

Figure 3. Voltage magnitude profile of Northern Nigeria.

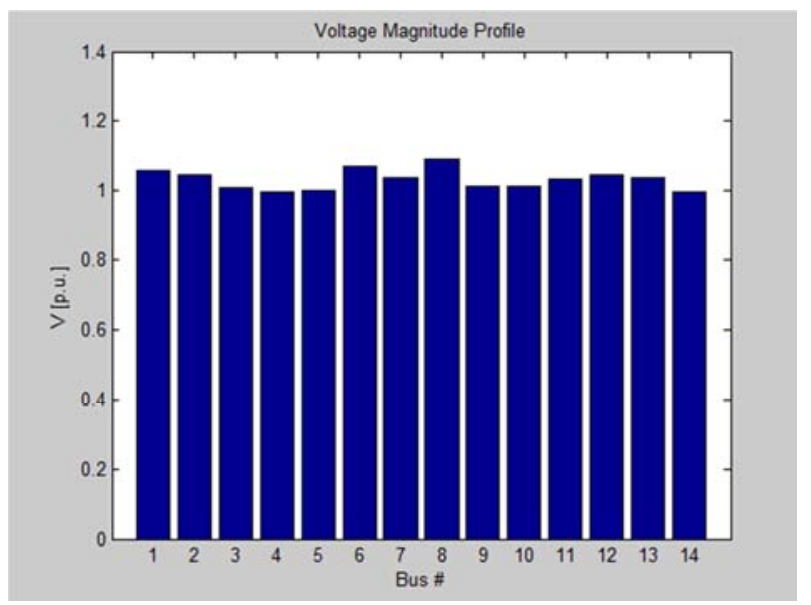

Figure 4. Voltage magnitude profile of IEEE 14 bus test.

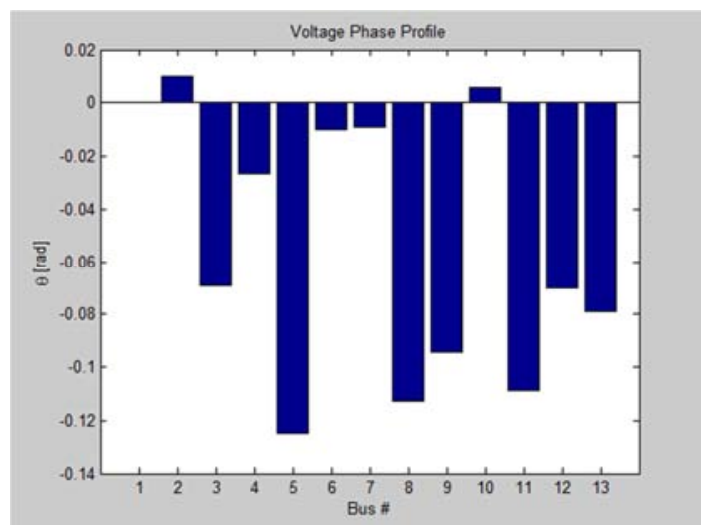

Figure 5. Voltage phase Profile of Northern Nigeria.

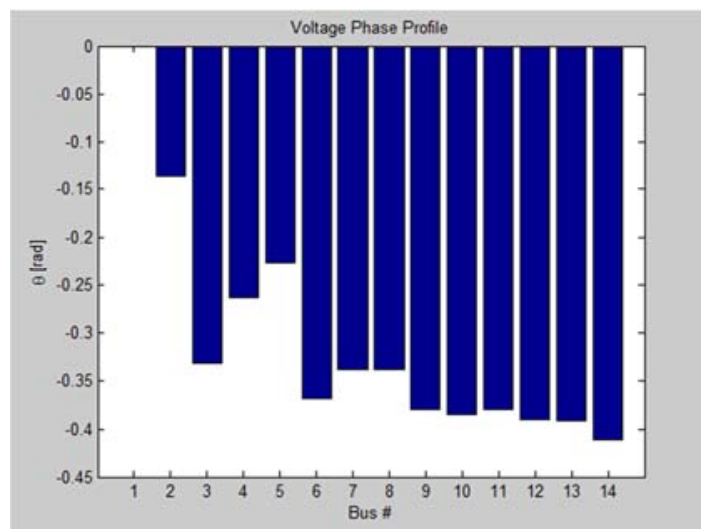

Figure 6. Voltage Phase Profile of IEEE 14 bus test.

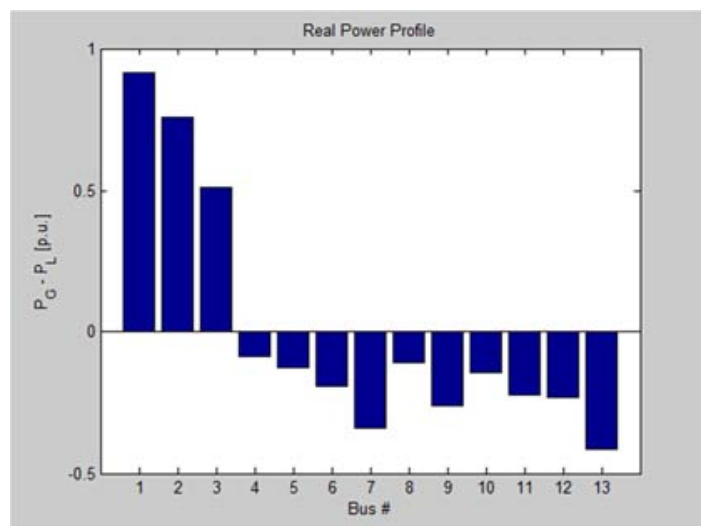

Figure 7. Real Power Profile of Northern Nigeria.

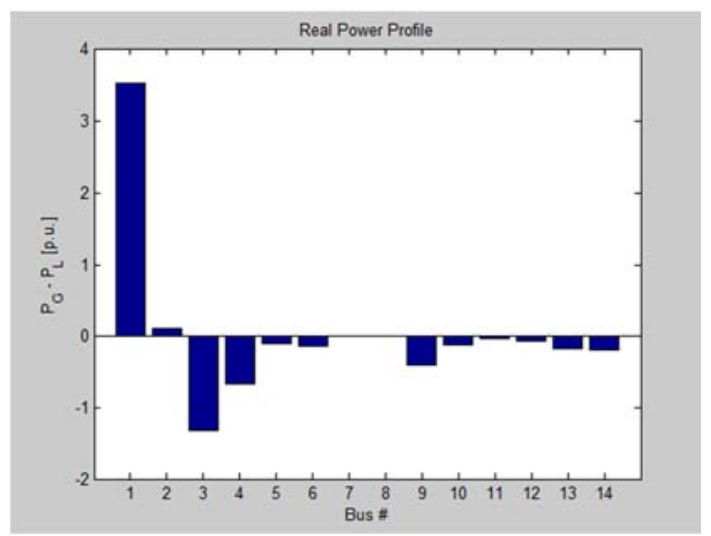

Figure 8. Real power profile of IEEE 14 bus test. 


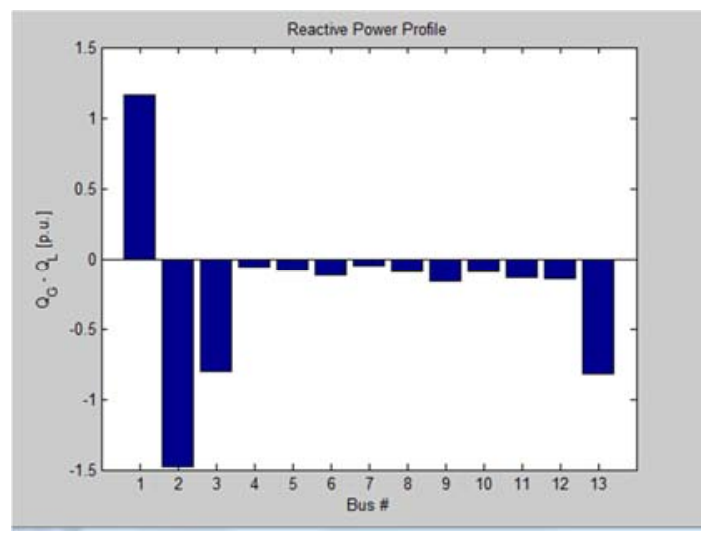

Figure 9. Reactive power profile of Northern Nigeria.

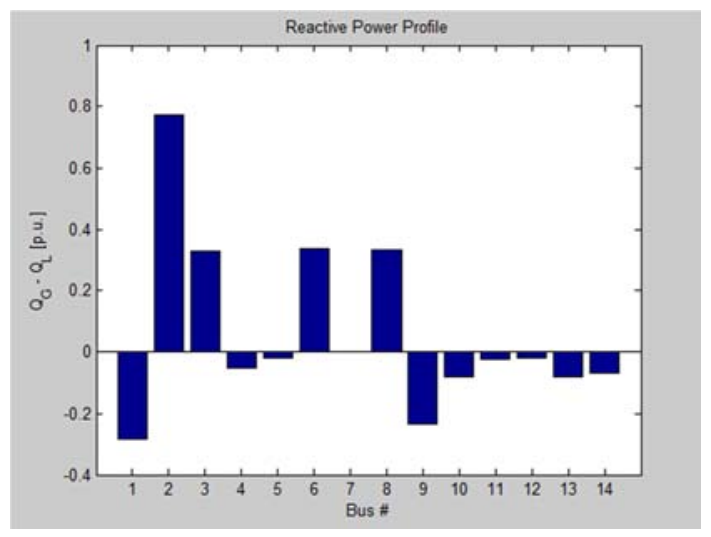

Figure 10. Reactive power profile of IEEE 14 bus test.

Table 1. Solution Statistics.

\begin{tabular}{lll}
\hline DESCRIPTION OF ITEM & IEEE 14 BUS & NORTHERN NIGERIA \\
\hline Number of Iterations & 9 & 4 \\
Maximum P Mismatch [p.u] & 0 & 0 \\
Maximum Q Mismatch [p.u] & 0 & 0 \\
Power rate [MVA] & 100 & 100 \\
\hline
\end{tabular}

Table 2. Power Flow Result of Northern Nigeria.

\begin{tabular}{lllllll}
\hline Bus & $\mathbf{V}[\mathbf{P . u}]$ & Phase $[\mathbf{r a d}]$ & $\mathbf{P}_{\text {Gen }}[\mathbf{P . u}]$ & $\mathbf{Q}_{\text {Gen }}[\mathbf{P . u}]$ & $\mathbf{P}_{\text {Load }}[\mathbf{P . u}]$ & $\mathbf{Q}_{\text {Load }}[\mathbf{P . u}]$ \\
\hline Bus 01 & 1.05000 & 0.00000 & 0.91476 & 1.1616 & 0.00000 & 0.00000 \\
Bus 02 & 1.00100 & 0.00994 & 0.75600 & -1.4766 & 0.00000 & 0.00000 \\
Bus 03 & 1.02100 & -0.06914 & 0.51300 & -0.8082 & 0.00000 & 0.00000 \\
Bus 04 & 1.03400 & -0.02651 & 0.00000 & 0.00000 & 0.08900 & 0.05500 \\
Bus 05 & 1.11480 & -0.12489 & 0.00000 & 0.00000 & 0.13000 & 0.08000 \\
Bus 06 & 1.03280 & -0.01000 & 0.00000 & 0.00000 & 0.19400 & 0.12000 \\
Bus 07 & 1.03510 & -0.00915 & 0.00000 & 0.00000 & 0.33900 & 0.04900 \\
Bus 08 & 1.09950 & -0.11266 & 0.00000 & 0.00000 & 0.11400 & 0.09000 \\
Bus 09 & 1.05290 & -0.09417 & 0.00000 & 0.00000 & 0.26000 & 1.16100 \\
Bus 10 & 1.00470 & 0.00575 & 0.00000 & 0.00000 & 0.14600 & 0.09000 \\
Bus 11 & 1.05710 & -0.10890 & 0.00000 & 0.00000 & 0.22600 & 0.14000 \\
Bus 12 & 1.02040 & -0.07080 & 0.00000 & 0.00000 & 0.23600 & 0.14600 \\
Bus 13 & 0.99807 & -0.07898 & 0.00000 & 0.00000 & 0.41300 & 0.82300 \\
\hline
\end{tabular}

Table 3. Power Flow Result IEEE 14-Bus Test System.

\begin{tabular}{lllllll}
\hline Bus & $\mathbf{V}[\mathbf{P} . \mathbf{u}]$ & Phase $[\mathbf{r a d}]$ & $\mathbf{P}_{\text {Gen }}[\mathbf{P . u}]$ & $\mathbf{Q}_{\text {Gen }}[\mathbf{P . u}]$ & $\mathbf{P}_{\text {Load }}[\mathbf{P . u}]$ & $\mathbf{Q}_{\text {Load }}[\mathbf{P . u}]$ \\
\hline Bus 01 & 1.06000 & 0.00000 & 3.35730 & 0.78985 & 0.00000 & 0.00000 \\
Bus 02 & 1.00090 & -0.11932 & 0.57784 & 0.30000 & 0.30380 & 0.17780 \\
Bus 03 & 0.93206 & -0.33419 & 0.00000 & 0.40000 & 1.31880 & 0.26600 \\
Bus 04 & 0.93066 & -0.25988 & 0.00000 & 0.00000 & 0.66920 & 0.05600 \\
Bus 05 & 0.94205 & -0.22069 & 0.00000 & 0.00000 & 0.10640 & 0.02240 \\
Bus 06 & 0.96224 & -0.39544 & 0.00000 & 0.24000 & 0.15680 & 0.10500 \\
Bus 07 & 0.94209 & -0.36556 & 0.00000 & 0.00000 & 0.00000 & 0.00000 \\
Bus 08 & 0.98501 & -0.35556 & 0.00000 & 0.24000 & 0.00000 & 0.00000 \\
Bus 09 & 0.91460 & -0.42345 & 0.00000 & 0.00000 & 0.41300 & 0.02324 \\
Bus 10 & 0.91087 & -0.42733 & 0.00000 & 0.00000 & 0.12600 & 0.08120 \\
Bus 11 & 0.93046 & -0.41503 & 0.00000 & 0.00000 & 0.04900 & 0.02520 \\
Bus 12 & 0.93675 & -0.42244 & 0.00000 & 0.00000 & 0.08540 & 0.02240 \\
Bus 13 & 0.92694 & -0.42495 & 0.00000 & 0.00000 & 0.18900 & 0.08120 \\
Bus 14 & 0.89044 & -0.45658 & 0.00000 & 0.00000 & 0.20860 & 0.07000 \\
\hline
\end{tabular}


Table 4. Line Flows of Northern Nigeria.

\begin{tabular}{lllllll}
\hline From Bus & To Bus & Line & P $_{\text {Flow }}[$ P.u $]$ & QFlow $_{\text {P.u }]}$ & P $_{\text {Loss }}[$ P.u $]$ & Q $_{\text {Loss }}[$ P.u $]$ \\
\hline Bus 06 & Bus 07 & 1 & -0.57320 & -1.15370 & 0.00031 & -0.00739 \\
Bus 06 & Bus 10 & 2 & -0.51126 & 1.20420 & 0.00577 & -0.12186 \\
Bus 10 & Bus 04 & 3 & 0.08968 & -0.24788 & 0.00068 & -0.30288 \\
Bus 06 & Bus 12 & 4 & 0.89046 & -0.17058 & 0.0072 & -0.45108 \\
Bus 12 & Bus 13 & 5 & 0.41568 & 0.65089 & 0.000268 & -0.17211 \\
Bus 09 & Bus 12 & 6 & -.073601 & 1.17010 & 0.00744 & -0.14694 \\
Bus 09 & Bus 11 & 7 & 0.22651 & -0.35827 & 0.00051 & -0.49827 \\
Bus 08 & Bus 09 & 8 & -0.24494 & 0.54136 & 0.00456 & -0.43144 \\
Bus 05 & Bus 08 & 9 & -0.13000 & -0.08000 & 0.000094 & -0.71136 \\
Bus 01 & Bus 07 & 10 & 0.91476 & 1.16160 & 0.00225 & -0.03363 \\
Bus 02 & Bus 10 & 11 & 0.75600 & -1.47660 & 0.00329 & -0.0074 \\
Bus 03 & Bus 12 & 12 & 0.51300 & -0.80282 & 0.00113 & -0.00221 \\
\hline
\end{tabular}

Table 5. Line Flows of IEEE 14 Bus Network Systems.

\begin{tabular}{lllllll}
\hline From Bus & To Bus & Line & P $_{\text {Flow }}[$ P.u $]$ & QFlow $_{\text {P.u. }}$ & P $_{\text {Loss }}[$ P.u $]$ & QLoss $_{\text {[P.u] }}$ \\
\hline Bus 02 & Bus 05 & 1 & 0.604090 & 0.15190 & 0.022370 & 0.036170 \\
Bus 06 & Bus 12 & 2 & 0.115200 & 0.04181 & 0.000199 & 0.004150 \\
Bus 12 & Bus 13 & 3 & 0.027800 & 0.01526 & 0.000125 & 0.000230 \\
Bus 06 & Bus 13 & 4 & 0.267080 & 0.12811 & 0.006270 & 0.012340 \\
Bus 06 & Bus 11 & 5 & 0.131930 & 0.09165 & 0.002650 & 0.005540 \\
Bus 11 & Bus 10 & 6 & 0.080280 & 0.06090 & 0.000960 & 0.002250 \\
Bus 09 & Bus 10 & 7 & 0.046790 & 0.02282 & 0.000100 & 0.000270 \\
Bus 09 & Bus 14 & 8 & 0.113800 & 0.02987 & 0.002100 & 0.004470 \\
Bus 14 & Bus 13 & 9 & -0.096900 & -0.04460 & 0.002450 & 0.004990 \\
Bus 07 & Bus 09 & 10 & 0.452560 & 0.24844 & 0.000000 & 0.033040 \\
Bus 01 & Bus 02 & 11 & 2.278400 & 0.40970 & 0.092870 & 0.227430 \\
Bus 03 & Bus 02 & 12 & -0.999710 & 0.00238 & 0.054080 & 0.186890 \\
Bus 03 & Bus 04 & 13 & -0.319090 & 0.13162 & 0.009510 & -0.005700 \\
Bus 01 & Bus 05 & 14 & 1.078800 & 0.38014 & 0.063960 & 0.214570 \\
Bus 05 & Bus 04 & 15 & 0.819200 & 0.00542 & 0.010100 & 0.020630 \\
Bus 02 & Bus 04 & 16 & 0.801700 & 0.16807 & 0.039300 & 0.084320 \\
Bus 04 & Bus 09 & 17 & 0.121150 & 0.08266 & 0.000120 & 0.012970 \\
Bus 05 & Bus 06 & 18 & 0.671000 & 0.25348 & 0.000000 & 0.126910 \\
Bus 04 & Bus 07 & 19 & 0.452560 & 0.06724 & 0.000000 & 0.048340 \\
Bus 08 & Bus 07 & 20 & 0.000000 & 0.24000 & 0.000000 & 0.010460 \\
\hline
\end{tabular}

\subsection{Discussion of Result}

It can be seen that from figure 3 Bus 05, Bus 09, and Bus 11 have exceed the voltage limit of 1.05 p.u and the reactive power generated by generator 2 at Bus 02 and generator 3 at Bus 03 are high. Base on the global summary, Real power generated was $218.38 \mathrm{MW}(2.1838$ p.u) and total reactive power of $-111.78 \mathrm{Mvar}(-1.1178 \mathrm{p.u})$ and total Load demand was Real power 214.7MW (2.147 p.u) and Reactive power 175.4 Mvar (1.754 p.u) and total losses due to transmission line was Real power 3.678 MW (0.003676 p.u), Reactive power -287.18 Mvar (-2.8718 p.u). The reactive power loss is higher than the reactive power generated. From table 4 it can be seen that between Bus 05 to Bus 08 i.e. Line 9 the reactive power loss is high and between Bus 09 to Bus 12 i.e. Line 6 has the highest real power loss of $0.744 \mathrm{MW}$.

\subsection{Conclusion}

From the result discussed, one can say that the power generated in Northern Nigeria is not adequate to meet the increasing demand. However, the available power generated also suffers losses due to ageing transmission lines and other power equipment.

\section{Acknowledgements}

Special Thanks goes to Power Holding Company for supplying us with the data needed for this research work.

\section{References}

[1] Sambo A. S, Garba B., I. H Zarma and M. M. Gaji, “Electricity Generation and Present challenges in the Nigerian Power Sector". Unpublished paper, Energy Commission of Nigeria, Abuja-Nigeria, 2010.

[2] Onohaebi S. O and Omorogiuwa Eseosa "Smart Grid and Energy Management in Nigeria Integrated Power System". International Journal of Engineering Innovation \& Research Vol.3, issue 6, ISSN: 2277-5668 October 2014.

[3] E. Acha., V. G. Agelidis, O. Anaya - Lara, T. J. E. Miller., "Power Electronics Control in Electrical Systems" Newness Power Engineering Series 2002.

[4] Adepoju G. A, Komolafe O. A, Aborishade D. O. "Power Flow Analysis of the Nigerian Transmission System Incorporating Facts Controllers". International Journal of Applied Science and Technology. vol. 1 No. 5; September 2011. 
[5] Adebayo I. G, Aborishade D. O, and Oyesina K. A." Steady State Voltage Stability Enhancement Using Static Synchronous Series Compensator (SSSC); A Case Study of Nigerian 330KV Grid System" RJEAS 2013.

[6] Rajesh krishnasamy, Karuppasamypandiyan $M$. and A. Bhuvanesh "Power Flow Analysis of 230/110KV Substation using ETAP" Conference paper February 2014. ResearchGate.

[7] O. J Onojo, G. C Ononiwi and S. O Okozi. "Analysis of Power Flow of Nigerian 330KV Grid System (Pre and Post) Using Matlab" EJNAS. Vol. 1, issue 2, 2013.
[8] Aminu A. Maraf and Kangiwa U. Garba" Determination of Bus Voltages, Power Losses and Load Flow in the Northern Nigerian 330KV Transmission Sub-Grid" IJART Vol. 2, issue 3, March 2013.

[9] Nirbhaykumar N., "Methods for Load Flow Analysis of Weakly Meshed Distribution System Makwana” International Journal of Scientific and Research Publications, Volume 2, Issue 3, March 2012.

[10] Hadi Saadat "Power System Analysis" Third Edition 2012. 